\title{
Fixed minidose warfarin: a new approach to prophylaxis against venous thrombosis after major surgery
}

\author{
L POLLER, A McKERNAN, J M THOMSON, M ELSTEIN, P J HIRSCH, J B JONES
}

\begin{abstract}
A prospective study was carried out to see whether a small fixed dose of warfarin (1 $\mathrm{mg}$ daily) given before operation (mean 20 days) would prevent deep vein thrombosis in patients having major gynaecological surgery. One hundred and four patients were randomised into three groups: fixed minidose warfarin; full dose oral anticoagulation; and no treatment (controls). There was a significantly lower incidence of deep vein thrombosis in the minidose warfarin and full dose anticoagulant treatment groups $(9 \%(3 / 32)$ and $3 \%(1 / 35)$ respectively) than in the controls (30\%; 11/37) but no significant difference between the two anticoagulant treatment groups. Prothrombin time and the activated partial thromboplastin time were normal on the day of surgery in the warfarin treatment group, whereas times were prolonged in the group given full dose anticoagulation. Mean haemoglobin concentrations fell in all three groups after operation but the fall was significantly less in the minidose warfarin treatment group than after full dose anticoagulation. The benefit from full dose oral anticoagulant prophylaxis, based on a preoperative international normalised ratio of $1.5-2.5$ with rabbit brain Manchester reagent, was similar to the protection achieved in an oral anticoagulant treatment group controlled with human brain Manchester comparative reagent at a similar level of anticoagulation.
\end{abstract}

The lack of disturbance of normal haemostasis at the time of

\footnotetext{
UK Reference Laboratory for Anticoagulant Reagents and Control, Withington Hospital, Manchester M20 8LR

L POLLER, DSC, FRCPATH, director

A MCKERNAN, MB, MRCP, research registrar in haematology

J M THOMSON, PHD, MRCPATH, deputy director

Department of Obstetrics and Gynaecology, Withington Hospital,
Manchester M20 8LR

M ELSTEIN, MD, FRCOG, professor of obstetrics and gynaecology

P J HIRSCH, MD, FRCOG, consultant obstetrician and gynaecologist

J B JONES, FRCS, FRCOG, consultant obstetrician and gynaecologist

Correspondence to: Dr Poller.
}

operation together with a significant reduction in deep vein thrombosis may encourage surgeons to introduce minidose prophylaxis with warfarin.

\section{Introduction}

All forms of anticoagulant prophylaxis entail a risk of haemorrhage, which has prevented their widespread use during surgery. Conventional oral anticoagulant treatment begun before surgery and with the dose adjusted according to the prothrombin time is highly effective in preventing postoperative deep vein thrombosis ${ }^{1}$ but has never widely been adopted because of the risks. In a recent study warfarin given in a fixed dose regimen of $2 \mathrm{mg}$ daily prevented thrombosis of indwelling central venous catheters. ${ }^{2}$ We have therefore carried out a prospective study to see whether an even smaller fixed dose ( $1 \mathrm{mg}$ daily) might be effective during major surgery and safe as prophylaxis against deep vein thrombosis. Patients having major gynaecological surgery were randomised to receive a fixed dose warfarin regimen of $1 \mathrm{mg}$ daily, full dose oral anticoagulation, or no treatment (controls) and monitored for deep vein thrombosis postoperatively.

\section{Patients and methods}

One hundred and four patients aged $\mathbf{4 0}$ or more who were having major gynaecological (abdominal or vaginal) surgery were randomly allocated to three groups: fixed minidose warfarin; full dose oral anticoagulation; and no treatment (controls). Randomisation was by random number tables. Patients with a history of deep vein thrombosis were excluded, as we thought it unwise to deny them conventional prophylaxis. All patients gave fully informed consent, and postoperative care was similar in the three groups.

Group 1-Warfarin in a fixed dose of $1 \mathrm{mg}$ daily was started before operation and continued in the same fixed dose throughout the patient's stay in hospital. The aim was to give a minimum of 14 days' treatment before operation. The day of admission was beyond our control, however, so that the actual duration of treatment before surgery ranged from six to 42 days, with a mean of 20 . Blood samples were collected from all patients for estimation of prothrombin time (with Manchester rabbit brain thromboplastin) and activated partial thromboplastin time (with Manchester APTT reagent) before treatment, during the 24 hours before operation, and on days $1,2,3$, and 5 after surgery. 
Group 2-Full dose oral anticoagulant treatment was begun with an induction dose of $6 \mathrm{mg}$ nicoumalone given at least five days before surgery. Subsequent doses were adjusted in the usual way according to the prothrombin time. The optimum intensity of anticoagulation on the morning of operation was considered to be an international normalised ratio of $1 \cdot 5-2 \cdot 5$ with use of the Manchester reagent. The activated partial thromboplastin time was estimated in parallel with the prothrombin time in all patients so that depression of intrinsic clotting factors could also be monitored. Nicoumalone dosage was subsequently monitored to maintain the international normalised ratio within the range 2:0-4.0 with the Manchester reagent. Full dose oral anticoagulation was continued until discharge and then withdrawn abruptly.

Group 3-Controls did not receive any form of anticoagulant or antithrombotic treatment. Blood samples were collected the day before operation and at similar times to the fixed dose warfarin treatment group after operation. Prothrombin times and activated partial thromboplastin times were estimated as in the warfarin treatment group.

Diagnosis of deep vein thrombosis-Impedance plethysmography was performed after seven days, or on the day of discharge if this was sooner, in all patients according to the technique described by Hull et al. ${ }^{3}$ All patients were also monitored by iodine-125 labelled fibrinogen scanning. Counts were taken at $10 \mathrm{~cm}$ intervals on both legs. The criterion for a positive scan was a $20 \%$ increase compared with the immediate postoperative reading, adjacent readings, or reading over the corresponding part of the opposite leg sustained for 24 hours. Scanning began immediately after operation and continued daily until the patient was discharged. At weekends all patients were monitored on at least one of the two days (mean seven days). Patients in all groups who had a positive scan were protected by immediate full dose oral anticoagulation (international normalised ratio $2 \cdot \mathbf{0 - 4 \cdot 0}$ ) or monitored daily by impedance plethysmography for any sign of progression. Two patients (one in group 1, the other in group 3) were subsequently given heparin and full dose oral anticoagulation after evidence of extension of deep vein thrombosis on impedance plethysmography. Ultrasonography was performed daily in all groups during their stay in hospital. All the ${ }^{125}$ I-fibrinogen scans, impedance plethysmography, and ultrasound examinations were performed by $\mathrm{AM}$.

Assessment of bleeding-Numbers of bleeding episodes in the three groups and haemoglobin concentrations were recorded routinely before operation and on the second postoperative day.

\section{Results}

The three groups were well matched for age and types of operation. Mean durations of hospital stay in the three groups were: controls 7.0 days; full dose anticoagulant treatment group $7 \cdot 2$ days; fixed dose warfarin treatment group 6.8 days. Both patients with malignancy had been randomised to the control group (table I). The full dose oral anticoagulant and minidose warfarin treatment groups showed a significantly lower incidence of deep vein thrombosis $(3 \%(1 / 35)$ and $9 \%(3 / 32)$ respectively) than the controls $(30 \% ; 11 / 37)$ (table II). Further analysis was performed excluding the two patients with malignancy; this did not affect the significance of the reduction in deep vein thrombosis in the fixed dose warfarin and full

TABLE I-Mean ages and types of operations performed in the three groups of patients (incidence of deep vein thrombosis given in parentheses)

\begin{tabular}{lccc}
\hline & $\begin{array}{c}\text { Full dose } \\
\text { oral anticoagulant } \\
\text { treatment group }\end{array}$ & $\begin{array}{c}\text { Fixed dose } \\
\text { warfarin } \\
\text { treatment group }\end{array}$ & Controls \\
\hline Mean age (years) & $49 \cdot 2$ & $51 \cdot 3$ & $48 \cdot 6$ \\
No having hysterectomy or laparotomy & $23(0)$ & $18(2)$ & $22(6)$ \\
No having pelvic floor repair & $12(1)$ & $14(1)$ & $15(5)$ \\
No with malignancy & 0 & 0 & $2(1)$ \\
\hline
\end{tabular}

TABLE II-Incidence of deep vein thrombosis

\begin{tabular}{lccc}
\hline \multicolumn{1}{c}{ Treatment group } & $\begin{array}{c}\text { Total } \\
\text { No of } \\
\text { patients }\end{array}$ & $\begin{array}{c}\text { No with } \\
\text { deep vein } \\
\text { thrombosis }\end{array}$ & $\begin{array}{c}\text { p Value } \\
\text { compared } \\
\text { with controls }\end{array}$ \\
\hline $\begin{array}{l}\text { Full dose anticoagulation } \\
\text { Fixed dose warfarin }\end{array}$ & 35 & 1 & $<0.01$ \\
Controls & 32 & 3 & 0.03 \\
\hline
\end{tabular}

^Fisher's exact test. dose anticoagulant treatment groups. Of the 15 patients with deep vein thrombosis, all had positive ${ }^{125}$ I-fibrinogen scans and one also had positive findings on impedance plethysmography. With this one exception all cases of deep vein thrombosis were in calf or popliteal veins. Ultrasonic results were negative in all patients.

The duration of warfarin treatment before surgery varied between six and 42 days (mean 20 days). The three patients suffering deep vein thrombosis in this group had received six, 15 , and 26 days of treatment respectively before surgery. Of the patients given full dose anticoagulation, $29(83 \%)$ had immediate preoperative values within the prothrombin time target range of the international normalised ratio.

The one patient in the full dose anticoagulant treatment group who developed deep vein thrombosis showed inadequate preoperative anticoagulation (international normalised ratio 1.2 with a normal activated partial thromboplastin time), though five others with an international normalised ratio of less than 1.5 on the day of operation did not show any evidence of deep vein thrombosis. There was a $0.5 \mathrm{~s}$ prolongation of the mean prothrombin time on the day before operation in the fixed dose warfarin treatment group compared with baseline values (paired $t$ test; $\mathrm{p}<0.01$ ) (fig 1). Nevertheless, the mean value was still well within the

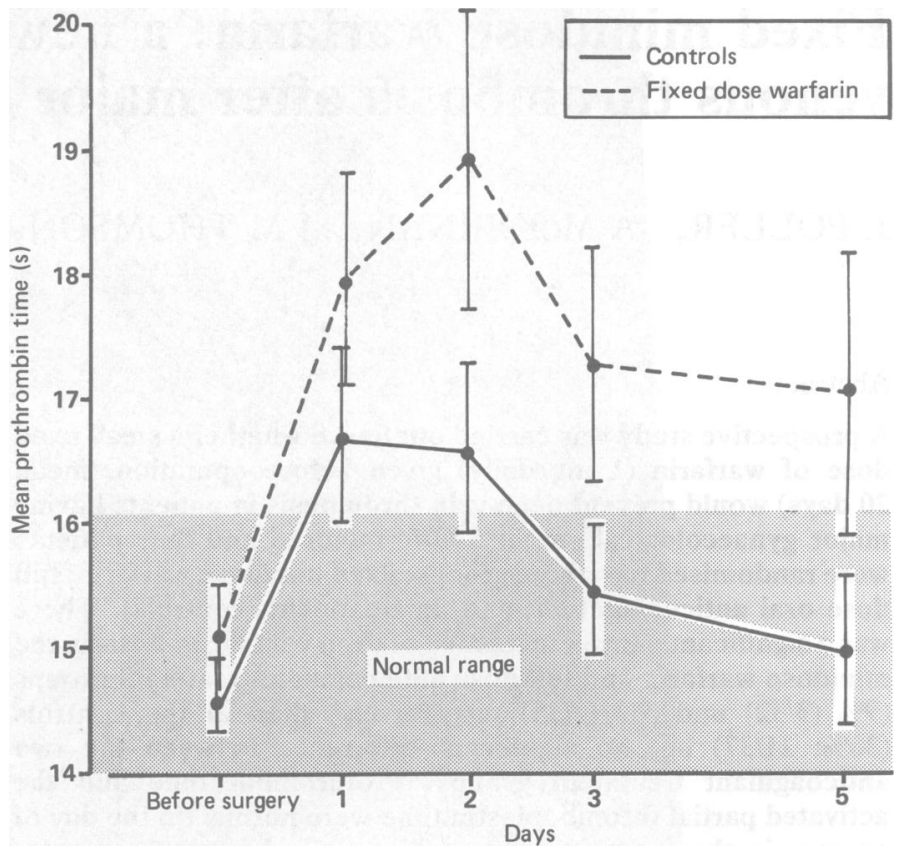

FIG 1-Prothrombin time results in fixed dose warfarin treatment group and controls before and after surgery. Bars are 2 SE.

normal range and not significantly different from the mean in the controls at the same stage. Four of the 32 patients given the fixed dose of warfarin had a prothrombin time outside the upper limit of normal on the day of operation (maximum prolongation $1 \cdot 2 \mathrm{~s}$ with Manchester reagent). Both the fixed dose warfarin treatment group and the controls showed significant prolongation of prothrombin times against their initial (baseline) values on the first, second, and third days after operation (two sample $t$ test, $\mathrm{p}<0.01$ ). The fixed dose warfarin treatment group continued to show significant prolongation on the fifth postoperative day $(p<0.01)$. Furthermore, on days 2,3 , and 5 the prolongation of the prothrombin time in the fixed dose warfarin treatment group was significantly greater than in the controls $(p<0.01)$ and outside the normal range, whereas on day 1 this prolongation was only just significant at the $5 \%$ level. The result on days 1 and 2 in the controls was beyond the upper limit of normal.

Ten patients in the fixed dose warfarin treatment group did not show any measurable preoperative prolongation of the prothrombin time compared with their baseline results. Two of these sustained a deep vein thrombosis. Only one of 22 patients who showed a preoperative prolongation of the prothrombin time with warfarin suffered a deep vein thrombosis.

The activated partial thromboplastin time became progressively accelerated after surgery in the control group compared with preoperative results, reaching a minimum mean value of $34 \cdot 1 \mathrm{~s}$ on the third postoperative day (fig 2). This difference was significant from the second postoperative day onwards $(p<0.01)$. The result on day 3 was less than the lower limit of normal with the Manchester APTT reagent method (36.0 s). Similar acceleration of the activated partial thromboplastin time was not found in the \& గ్ర ๗ $\overrightarrow{0}$ 


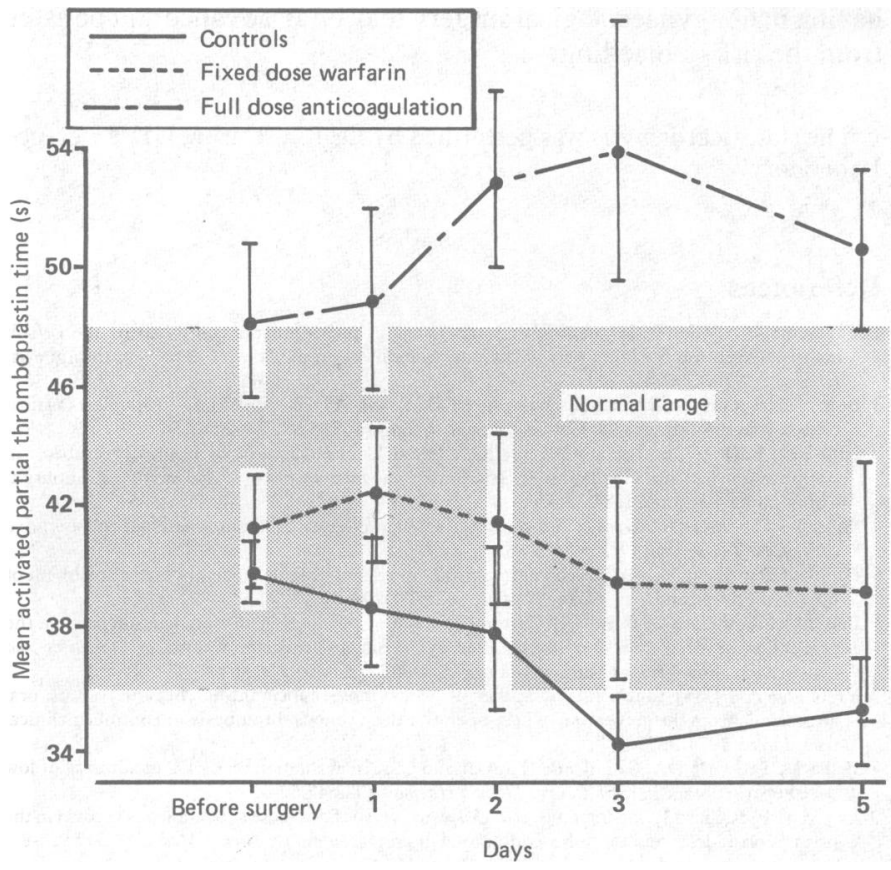

FIG 2-Activated partial thromboplastin time results in the three groups before and after surgery. Bars are $2 \mathrm{SE}$.

fixed dose warfarin treatment group after surgery compared with baseline values. Full dose anticoagulation, on the other hand, greatly prolonged the activated partial thromboplastin time compared with the warfarin treated and control patients.

Table III shows the mean changes in haemoglobin concentrations. All three groups showed a fall in values. This was significantly less with fixed dose warfarin treatment than with full dose anticoagulation. There was, however, no difference between the full dose anticoagulant treatment group and the controls and no difference between the warfarin treated group and controls. There was no significant difference in excessive bleeding among the groups, though the incidence of haemorrhage was lowest with warfarin (table IV). Table V gives the estimated relative risks of deep vein thrombosis and haemorrhage among the three groups with $95 \%$ confidence intervals.

TABLE III-Falls in haemoglobin concentration

\begin{tabular}{lccc}
\hline \multicolumn{1}{c}{ Treatment group } & $\begin{array}{c}\text { Total } \\
\text { No of } \\
\text { patients }\end{array}$ & $\begin{array}{c}\text { Mean fall in } \\
\text { haemoglobin } \\
(\mathrm{g} / \mathrm{l})^{\star}\end{array}$ & $\begin{array}{c}95 \% \\
\text { Confidence } \\
\text { interval }\end{array}$ \\
\hline Full dose anticoagulation & 35 & $23 \cdot 4$ & $18 \cdot 5$ to $28 \cdot 3$ \\
Fixed dose warfarin & 32 & 16.9 & $13 \cdot 7$ to $20 \cdot 0$ \\
Controls & 37 & $18 \cdot 7$ & $14 \cdot 3$ to 23.0 \\
\hline
\end{tabular}

^All means significantly greater than zero $(p<0.01)$.

TABLE IV-Incidence of haemorrhage: wound haematoma or transfusion for excessive haemorrhage, or both

\begin{tabular}{lccc}
\hline \multicolumn{1}{c}{ Treatment group } & Total No of patients & Haemorrhage & No transfused \\
\hline Full dose anticoagulation & 35 & 8 & 4 \\
Fixed dose warfarin & 32 & 4 & 1 \\
Controls & 37 & 5 & 4
\end{tabular}

TABLE V-Estimated relative risks and $95 \%$ confidence intervals. Figures are percentages

\begin{tabular}{|c|c|}
\hline $\begin{array}{l}\text { ncidence of } \\
\text { deep vein } \\
\text { hrombosis }\end{array}$ & $\begin{array}{c}\text { Incidence } \\
\text { of } \\
\text { haemorrhage }\end{array}$ \\
\hline (6 to 97 & $\begin{array}{r}190(55 \text { to } 650) \\
91(22 \text { to } 374) \\
207(56 \text { to } 770)\end{array}$ \\
\hline
\end{tabular}

\section{Discussion}

The value of a fixed dose of warfarin in preventing thrombosis in central line catheters was recently reported by Bern et al. ${ }^{2}$ They used $2 \mathrm{mg}$ warfarin daily but in some patients this resulted in overtreatment and the need for vitamin $\mathrm{K}_{1} .{ }^{2}$ Our aim was to see whether a smaller fixed dose of warfarin which would not interfere with haemostasis at operation would be effective in preventing deep vein thrombosis in patients having major surgery. The dose of $1 \mathrm{mg}$ daily was much less than the range of mean daily maintenance doses of warfarin $(2 \cdot 5-6 \cdot 0 \mathrm{mg})$ reported in an international collaborative survey ${ }^{4}$ and less than the mean maintenance dose of $5.8 \mathrm{mg}$ used in the Simplastin controlled group and $4.9 \mathrm{mg}$ in the Manchester comparative reagent controlled group studied by Hull et al. ${ }^{5}$ Patients in our study were randomised to receive fixed dose warfarin, full dose oral anticoagulation, or no treatment (oral anticoagulant prophylaxis is not normally undertaken in women having major abdominal or vaginal surgery).

Our results show that a small fixed dose of warfarin given for a mean of three weeks before operation protects against deep vein thrombosis in major gynaecological surgery. Nevertheless, the relative incidences of deep vein thrombosis (table $V$ ) had wide confidence intervals owing to the low incidence rates in this small trial. Prophylaxis against deep vein thrombosis was achieved without prolonging the prothrombin time and activated partial thromboplastin time beyond normal on the day of operation. Surgery undertaken with this regimen did not appear to have been associated with increased bleeding compared with controls. Though all three groups showed a postoperative fall in haemoglobin concentrations, this was significantly less in the group given fixed dose warfarin compared with patients who received full dose anticoagulation. Thus it appears that protection against deep vein thrombosis may have been gained without the perioperative disturbance of haemostasis associated with full dose oral anticoagulation which has discouraged surgeons from using oral anticoagulant prophylaxis.

The oral route of anticoagulant treatment is considerably simpler and less traumatic than the repeated subcutaneous injections required with low dose heparin regimens which are currently recommended for prophylaxis against deep vein thrombosis. Further study is required to assess the relative effectiveness and safety from haemorrhage of fixed dose warfarin and low dose subcutaneous and low molecular weight heparins.

The incidence of deep vein thrombosis among our controls (30\%) was similar to that in a previous control group (23\%) during major gynaecological operations ${ }^{1}$ and that reported by Ballard et al in gynaecological patients $(29 \%) .^{6}$ The incidence of deep vein thrombosis in our full dose oral anticoagulant treatment group (3\%) was also similar to that in our previous study $(6 \%)$ but considerably lower than that reported by van Vroonhoven et al (18\%), who began prophylaxis only on the day of operation or the next day. ${ }^{7}$ The benefit from oral anticoagulant prophylaxis in full dosage with a preoperative target international normalised ratio of $1.5-2.5$ based on rabbit brain Manchester reagent and achieved in our study appeared to be similar to that in the oral anticoagulant treatment group maintained at a similar level of anticoagulation by using human brain thromboplastin (Manchester comparative reagent) described in our previous study. The full dose anticoagulant treatment group received nicoumalone rather than full dose warfarin so that the results would be comparable with those of our previous randomised study. ${ }^{1}$ In that study the nicoumalone series was compared with an untreated control group and patients receiving fixed dose subcutaneous heparin.

Though no pronounced change was noted in the coagulation test results on the day before operation in the fixed dose warfarin treatment group, the slight but significant prolongation of the prothrombin time at operation may have had a protective effect. Ten patients in this group did not show any prolongation of the prothrombin time at operation but two sustained a deep vein thrombosis. On the other hand, only one of 22 patients who showed a slight prolongation of the prothrombin time suffered deep vein thrombosis. A further possible protective effect may be the prevention of the postoperative acceleration of the activated partial 
thromboplastin time normally found in the first few days after surgery. With fixed dose warfarin, unlike in the control group, there was no acceleration of this procedure. Subcutaneous heparin given in effective doses may also prevent the postoperative acceleration of the activated partial thromboplastin time. ${ }^{89}$ Possibly the mechanism of protection may be similar with the two treatments. A contributory protective action may have been the prolongation by fixed dose warfarin of the prothrombin time in the days immediately after surgery. This was an exaggeration of the prolonged prothrombin time found in the control group over the same period.

The main attraction of fixed dose warfarin compared with full dose anticoagulation and heparin lies in the apparent lack of disturbance of normal haemostasis during surgery. Furthermore, no patient had a prothrombin time at this stage more than 1.2 seconds above the upper limit of normal with the Manchester reagent (international sensitivity index $1 \cdot 1 \pm 3 \%$ ), which is highly responsive to coumarin clotting factors. The study was too small to expect a significant difference in the incidence of bleeding among the groups, as evidenced by the wide confidence intervals in relative incidences of deep vein thrombosis and haemorrhage (table V); nevertheless, the reduction in the fall of postoperative haemoglobin values in the fixed dose warfarin treatment group compared with full anticoagulation was encouraging. Further studies will be required fully to quantify the benefits. We, however, consider that this new approach to preventing venous thrombosis in patients having major gynaecological surgery may be an advance and be safer from the risk of bleeding.

The statistical analysis was performed by Dr K V Darby, UK Reference Laboratory.

\section{References}

1 Taberner DA, Poller L, Burslem RW, Jones JB. Oral anticoagulants controlled by the British comparative thromboplastin versus low dose heparin in prophylaxis of deep vein thrombosis. BrMed f 1978; ;:272-4.

2 Bern MM, Bothe A Jr, Bistrian B, Champagne CD, Keane MS, Blackburn GL. Prophylaxis against central vein thrombosis with low-dose warfarin. Surgery 1986;99:216-20.

3 Hull RD, Raskob GE, Leclerc JR, Jay RM, Hirsh J. The diagnosis of venous thrombosis in symptomatic patients. In: Poller $\mathrm{L}$, ed. Recent advances in blood coagulation 4. Edinburgh: Churchill Livingstone, 1984:39-43.

4 Poller $\mathrm{L}$, Taberner DA. Dosage and control of oral anticoagulants: an international collaborative survey. Brf Haematol 1982;51:479-85.

5 Hull R, Hirsh J, Jay R, et al. Different intensities of oral anticoagulant therapy in the treatment of proximal vein thrombosis. N Engl f Med 1982;307:1676-81.

6 Ballard RM, Bradley-Watson PJ, Johnstone FD, et al. Low doses of subcutaneous heparin in the prevention of deep vein thrombosis after gynaecological surgery. Fournal of Obstetrics and Gynaecology of the British Commonwealh 1973;80:469-72.

7 Vroonhoven TJMV van, Ziijl J, Muller $H$. Low dose subcutaneous heparin versus oral anticoagulants in the prevention of post-operative deep venous thrombosis. A controlled clinical trial. Lancet 1974;i:375-8.

8 Poller L, Taberner DA, Sandilands DG, Galasko CS. An evaluation of APTT monitoring of low dose heparin dosage in hip surgery. Thromb Haemost 1982;47:50-3.

9 Leyvraz PF, Richard J, Bachmann F, et al. Adjusted versus fixed-dose subcutaneous heparin in the prevention of deep vein thrombosis after total hip replacement. $N$ Engl F Med 1983;309:954-8.

(Accepted 13 October 1987)

\section{SHORT REPORTS}

\section{Hypophosphataemia in acute liver failure}

Hypophosphataemia has serious metabolic effects that may increase mortality in severe illness. ${ }^{1}$ Pronounced hypophosphataemia was reported in patients with alcoholic liver disease and presumed viral infection and in Reye's syndrome, ${ }^{23}$ while abnormal cerebral phosphate metabolism may play a part in chronic hepatic encephalopathy ${ }^{4}$ We examined the incidence and severity of hypophosphataemia in patients with acute liver failure.

\section{Patients, methods, and results}

The records of 13 patients treated for acute liver failure with coma (grade III-IV) between January 1985 and February 1987 were reviewed. The liver damage had been induced by paracetamol in 12 cases and by non-A, non-B hepatitis in one. The table shows details of age, sex, clinical course and grade of coma on admission, treatment, and outcome. Six of the patients $(46 \%)$, including the patient with non-A, non-B hepatitis, died. Factors known to cause hypophosphataemia ${ }^{1}$ were specifically recorded and correlated with plasma phosphate concentrations.

The mean plasma phosphate concentration on admission was 1.23 (SE 0.32 ) $\mathrm{mmol} / 1$ (normal range $0.70-1.45 \mathrm{mmol} / \mathrm{l}$ ), although three patients had low concentrations $(0.4,0.3$, and $0.01 \mathrm{mmol} / \mathrm{l})$. It did not correlate with age, time after ingestion or dose of paracetamol, coma grade, prothrombin time, serum alanine aminotransferase activity, blood glucose concentration, or $\mathrm{pH}$ on admission.

The mean lowest plasma phosphate concentration was $0.59(0.13) \mathrm{mmol} / \mathrm{l}$ Eight patients had at least one recording of less than $0.7 \mathrm{mmol} / \mathrm{l}$ and five had values of $0.3 \mathrm{mmol} / \mathrm{l}$ or less. The lowest plasma phosphate concentration showed a negative correlation with the hydrogen ion concentration measured concurrently $(r=-0.96, p<0.05)$ and a positive correlation with the serum creatinine

Clinical data and plasma phosphate concentrations in 13 patients treated for acute liver failure

\begin{tabular}{|c|c|c|c|c|c|c|c|c|c|}
\hline \multirow[b]{2}{*}{ Case No } & \multirow[b]{2}{*}{$\begin{array}{c}\text { Age } \\
\text { (years) }\end{array}$} & \multirow[b]{2}{*}{ Sex } & \multicolumn{2}{|c|}{ Paracetamol } & \multirow[b]{2}{*}{ Complications } & \multirow[b]{2}{*}{ Treatment ${ }^{\star}$} & \multirow[b]{2}{*}{$\begin{array}{l}\text { Clinical course } \\
\text { (coma grade and } \\
\text { outcome) }\end{array}$} & \multicolumn{2}{|c|}{ Phosphate (mmol/l) } \\
\hline & & & \multicolumn{2}{|c|}{$\begin{array}{c}\text { Time between } \\
\text { ingestion and } \\
\text { Dose }(\mathrm{g}) \text { presentation }(\mathrm{h})\end{array}$} & & & & $\begin{array}{l}\text { On } \\
\text { admission }\end{array}$ & $\begin{array}{l}\text { Lowest } \\
\text { value }\end{array}$ \\
\hline 1 & 23 & $\mathbf{F}$ & 15 & & None & Conservative & $\mathrm{I} \rightarrow \mathrm{III} \rightarrow$ Recovery & & 1.05 \\
\hline 2 & 64 & $\mathbf{F}$ & 50 & 144 & $\begin{array}{l}\text { Renal failure, gastrointestinal bleeding, } \\
\text { cerebral oedema }\end{array}$ & $\begin{array}{l}\text { Charcoal haemoperfusion, haemodialysis, } \\
\text { haemofiltration, mannitol infusion }\end{array}$ & $0 \rightarrow I V \rightarrow$ Death & $1 \cdot 29$ & $0 \cdot 34$ \\
\hline 3 & 43 & $\mathbf{M}$ & 100 & 72 & Renal failure, grand mal fit & Haemodialysis & $0 \rightarrow I V \rightarrow$ Recovery & 1.01 & 0.25 \\
\hline 4 & 54 & $\mathbf{F}$ & 20 & 20 & None & Conservative & $\mathrm{I} \rightarrow \mathrm{III} \rightarrow$ Recovery & 1.62 & 0.45 \\
\hline 5 & 18 & $\mathbf{F}$ & 30 & 48 & Cerebral oedema & Charcoal haemoperfusion, mannitol infusion & II $\rightarrow$ IV $\rightarrow$ Recovery & & $0 \cdot 23$ \\
\hline 6 & 23 & $\mathbf{M}$ & 35 & 14 & Renal failure & Charcoal haemoperfusion, haemodialysis & $\mathrm{I} \rightarrow \mathrm{III} \rightarrow$ Recovery & 0.81 & 0.81 \\
\hline 7 & 38 & $\mathbf{M}$ & 15 & 48 & $\begin{array}{l}\text { Renal failure, cerebral oedema, } \\
\text { gastrointestinal bleeding, disseminated } \\
\text { intravascular coagulation }\end{array}$ & Charcoal haemoperfusion, mannitol infusion & $\mathrm{I} \rightarrow \mathrm{IV} \rightarrow$ Death & $3 \cdot 25$ & $1 \cdot 36$ \\
\hline 8 & 50 & $\mathbf{F}$ & 25 & 72 & Renal failure & Haemodialysis & $0 \rightarrow I V \rightarrow$ Recovery & 1.07 & 0.84 \\
\hline 9 & 25 & $\mathbf{F}$ & 100 & 60 & Renal failure, cerebral oedema & Haemofiltration, mannitol infusion & $\mathrm{III} \rightarrow \mathrm{IV} \rightarrow$ Death & $2 \cdot 51$ & 0.51 \\
\hline 10 & 31 & M & 15 & 140 & Cerebral oedema & Mannitol infusion & $\mathrm{II} \rightarrow \mathrm{IV} \rightarrow$ Recovery & 0.01 & 0.01 \\
\hline 11 & 52 & $\mathbf{F}$ & 50 & 96 & $\begin{array}{l}\text { Renal failure, gastrointestinal bleeding, } \\
\text { cerebral oedema }\end{array}$ & Haemofiltration, mannitol infusion & $0 \rightarrow I V \rightarrow$ Death & 0.4 & 0.06 \\
\hline 12 & 37 & $\mathbf{F}$ & 6 & 72 & Renal failure, cerebral oedema & Haemofiltration, mannitol infusion & III $\rightarrow$ IV $\rightarrow$ Death & & 1.44 \\
\hline 13 & 24 & $\mathbf{F}$ & $t$ & $t$ & $\begin{array}{l}\text { Renal failure, gastrointestinal bleeding, } \\
\text { cerebral bleeding }\end{array}$ & $\begin{array}{l}\text { Charcoal haemoperfusion, plasma exchange, } \\
\text { haemofiltration, mannitol infusion }\end{array}$ & $0 \rightarrow I V \rightarrow$ Death & $0 \cdot 30$ & $0 \cdot 30$ \\
\hline
\end{tabular}

^All patients received intravenous glucose, lactulose, vitamin $\mathrm{K}$, and neomycin (in the absence of renal failure), with blood and clotting factors as necessary. tPatient had non-A, non-B hepatitis; liver failure developed 29 days after start of clinical illness. 